\title{
Beyond Pets: Exploring Relational Perspectives of Petness ${ }^{1}$
}

JEN WRYE

\begin{abstract}
Considerable work has examined the place of pets in humans' lives, although most of this research takes for granted that pets are certain animals. While these perspectives provide insight into the character of human-nonhuman relationships, the assumptions underlying such research frequently invest in a concept of pets as having essential qualities. This paper explores the possibility that petness, which can generally be defined as the state, quality, or conditions under which a pet is constituted, arises from social relations and the treatment of objects. Using the example of virtual pets I will argue that there is no essential "petness" to anything and that it is a social construct. More specifically, I contend that pets are the product of the investment of human emotion into objects. After outlining how such treatment is not exclusive to the animals that live close to us, but is similarly exhibited toward inanimate entities as well as other sentient creatures, I conclude with some discussion of how pet relations can be understood in the context of late capitalism.
\end{abstract}

Key Words: petness; pet; companion animal; virtual pet; relationships; attachment; Tamagotchi; social constructionism

Résumé. Beaucoup d'effort a été consacré à la place que les animaux de compagnie occupent dans la vie des humains bien que la plus grande partie de cet effort prenne pour acquis que ces animaux de compagnie sont justement des animaux. Ces points de vue donnent des perspectives sur la nature des relations entre humains et non humains; les hypothèses qui inspirent cette recherche investissent souvent dans une notion que les animaux de compagnie ont des qualités essentielles. Cet article explore la possibilité que de la nature-même d'un animal de compagnie que l'on pourrait, communément, définir comme étant la condition, la qualité ou l'état en vertu desquels l'animal de compagnie se constitue, résulte des relations sociales et du traitement d'objets. Si je prends l'exemple des tamagochis, je dirais qu'il n'y a pas absolument pas de nature spéciale d'animal de compagnie et qu'il s'agit d'une construction sociale. Plus précisément, je dirais

1. A version of this paper was presented at the annual meeting of the Canadian Association of Sociology, 2007, Saskatoon, Saskatchewan. The author is grateful to Daiva Stasiulis, Bruce Curtis, Neil Gerlach, Kevin Walby, and three anonymous reviewers for their insightful comments and guidance in preparation of this paper. Paul, Pia, Spencer, Piaextreme, and several Tamagotchi incarnations should also be acknowledged. 
que les animaux de compagnie sont le produit de l'investissement de l'émotion humaine dans des objets. Après avoir énoncé de quelle manière ce traitement n'est pas exclusif aux animaux qui vivent près de nous, mais qu'il existe aussi à l'égard d'entités inanimées et autres créatures sensibles, je conclue avec une discussion sur la manière de comprendre les relations avec les animaux de compagnie dans le contexte du capitalisme tardif.

Mots clés: pet; animaux de compagnie; animal virtuel; rapport; attachement; tamagochi; constructivisme social

Being cannot be anything but being-with-one-another - Jean-Luc Nancy

\section{INTRODUCTION}

ver twenty-five years ago, Clifton Bryant accused sociologists of failing to address the "zoological component" in human interaction and social systems. Sociologists, he claimed,

have often been myopic in their observations of human behaviour, cultural patterns and social relationships, and unfortunately have not taken into account the permeating social influence of animals in our larger cultural fabric, and our more idiosyncratic individual modes of interaction and relationships in their analyses of social life. (1979:400)

Since then, many sociologists have studied the prominence of animalhuman relations, and arguably one of the best researched areas concerns the subject of pets and pet keeping. A burgeoning literature has explored the origins, utility, benefits, costs, and even difficulties associated with the human practice of living with pet or companion animals; these relationships are among the most common and significant in contemporary Western societies. At least half of all households in the English speaking world have pets and nearly $90 \%$ of pet owners consider pets to be family members (Plous 1993:2; Siegal 1993:157-8, Kruuk 2002:137-8).

While pets have been the subject of a great deal of attention, few authors have theorized the relation that constitutes animals as pets or questioned the quality of what I will call "petness." Most researchers recognize that there is nothing inherent to being a pet and agree that animals are labeled and handled differently according to the arbitrariness of humans' practices (Eddy 2003a). What connects most work on pets, including the ethical, theoretical, and empirical research, is that "the pet" is assumed to be an animal. Yet pets may not be living creatures and nonliving pets are either unnoticed or dismissed as inferior and trivial. 
This is not to say there is no research on other types of pets, namely, virtual or inanimate pets that are not live animals (see Bickmore 1998; Bloch and Lemish 1999; Kritt 2000). Rather, what does exist has been largely marginalized to studies in new technologies, computers, or popular culture. Missing is a sociological examination of petness in its various manifestations. The literature on the question, "what is a pet," is problematic because it speaks to petness by looking at animals called pets rather than examining the larger social relation of petness and applying this framework to objects and animals.

This paper represents my attempt to rectify this situation by making a few simple arguments. I take the position that there is no essential "petness" to anything and that it is a social construction. I will argue that petness, which can generally be defined as the state, quality, or conditions under which a pet is constituted, arises from social relations and the treatment of objects. I contend that pets are a product of the investment of human emotion into objects, and that this is not exclusive to animals, but is also exhibited in our treatment of inanimate and inorganic entities.

\section{Of ObJects and Animals: Preliminary Conceptual Issues}

It is important to identify the limitations and boundaries of this work. My use of the term "object" to refer to all pets, including animals, may seem inappropriate since animals are sentient beings and virtual pets are inorganic machines. Sentience generally refers to the capacity to feel, particularly pleasure or pain. It is implied that this capacity operates through some sort of consciousness, is expressed in behaviour, and therefore, is measurable. Thus, sentience links with the ability to be responsive, attentive, alert, and so on. ${ }^{2}$ As I explain further below, even though there are obvious differences in their constitution, virtual pets show these capabilities. Of course it would be unwise to believe these emanate from any true selves in virtual pets. But having or lacking a self is not a prerequisite for being a social creature. For example, Hacking (1999) and Latour (1988b) have convincingly argued that society comprises both human and nonhuman "kinds" or "actants," who create material and social realities. Likewise, they note many situations in which these entities, aware or not, create interesting and novel forms of sociality. As pets, things become the objects of human intervention and interpretation. I take the position that a pet is an object because it is constituted in relation

2. Sentience is a more complex physiological, biological, and philosophical concept than I have intimated. In part, this is because sentience in other creatures (as well as some humans), is contested. For a richer discussion of sentience and its relationship with ethical decision-making, see Singer (1975). 
to a subject, which is independent of animal selfhood. Both animals and automated machines become pets by virtue of humans granting them, through various actions, such status. I recognize that animals are beings and not inanimate, like tables. But this quality, as important as it is, has no bearing on their designation as pets.

This essay is not an examination of the nature or characteristics of petness and I will not attempt to identify the criteria for classifying this relation. My aim here is more modest but, I believe, an important starting point for those who might take on those projects. Sociologists need to start talking relationally about the social form of petness. By exploring the case of interactive virtual pets, I will show that the tendency to define and unwittingly delimit the category of pet is problematic because social scientists are ignoring relationships that are important to people. We need to question the quality of these categories and interrogate the ways in which they are constructed.

A useful starting point lies in an explanation of why this is a valuable undertaking. Why is it important to differentiate between pets and pet relations? To frame this inquiry, Werner Herzog's 2005 documentary film, Grizzly Man, is instructive in a number of ways. Grizzly Man is the story of amateur grizzly bear specialist and activist, Timothy Treadwell who, with Amie Hugeunard, was mauled and killed in an October 2003 bear attack. For thirteen years, Treadwell journeyed to Alaska's Katmai National Park Preserve to study and live among grizzly bears. During his last four trips, he shot over 100 hours of video detailing bear life, and in telling this story, Herzog relies considerably on Treadwell's own footage. But the recordings are more than just distant shots of bears eating, fighting and so on. Treadwell tapes himself as an active participant-observer. $\mathrm{He}$ is frequently shown near the bears, engaging with them verbally and even physically. It is this feature which is particularly fascinating because Treadwell moves beyond making observations about bears to talk about himself and his place among them. It becomes obvious that he believes the animals to be his companions. For instance, he names most of the bears and describes them as individuals who behave distinctively. He sings and reads to them, and frequently uses "baby talk" in his communications. He regularly expresses his affection for them, proclaiming: "I love you, I love you" and "You're so beautiful, aren't you?" He refers to the bears and also some foxes as friends, particularly a "favorite" bear named Mr. Chocolate, who "has been with [him] for over a decade [and is] a good friend" (emphasis mine).

The character and depth of Treadwell's feelings is not lost on the many people, including his friends and family, as well as bear and wildlife experts, who provide perspective on his conduct. Their opinions are 
exceptionally polarized as each reflects on Treadwell's relationship with these wilderness animals. While some defend his deep adoration of, and devotion toward, the grizzlies, others are more critical of his actions and intentions. His behaviour has been described as a type of disrespectful interference that puts both bears and humans at risk. He was also accused by many of having an "unhealthy" relationship with the animals, misguidedly portraying them as cuddly companions rather than as "the ferocious wild animals they are." One critic even alleged that "he had lost sight of what was really going on; got what he was asking for, what he deserved."

One of the most salient features of the film was the nearly unanimous disapproval of Treadwell's connection to the bears. Many people remarked that Treadwell treated them "like pets" and either implied or explicitly stated that this was wrong. But why can't bears, or any other entity for that matter, be a pet? Certainly bears, as well many reptiles, land and aquatic mammals, sea creatures, insects, fish, and birds, are not commonly kept or known as pets. Should this disqualify them from being such?

There are two related problems with the claim that certain animals or objects cannot be pets. First, to do so would be entirely essentialist. Investing in objects necessitates identifying those characteristics which any entity must have to belong to a particular group. If we exclude certain objects from the category, then we concede the basis for our classification lies in the properties of things instead of the way we are connected to them (Emirbayer 1997). Using the example of virtual pets, I hope to show that this approach cannot be sustained; we must take a constructionist approach to understanding pet relations. Second, the view that there is something inherent about being a pet creates a boundary, with the attendant difficulties of defending it. This necessitates excluding some things even if they are thought of and treated as if they are pets. Knowledge of pets becomes partial with gaps, omissions, and exclusions; how we describe or account for certain characteristics of modern social life is limited. This is exactly what has happened with petness - it has been instantiated.

Sociologists and other scholars, particularly those who work in the field of animal-human relations, should be extremely wary of such a prospect. Investing in a pet/nonpet dualism suspiciously resembles assertions of human exceptionalism that situate humans in opposition to animals. The animal/human divide remains a key feature of modern life. As Bingham (2006:490) puts it:

we need to deal with a philosophical inheritance according to which other 
things than the human are always defined by their lack in comparison with 'us.' Lack of language, lack of consciousness, lack of reason, lack of authenticity; the hegemonic (if never homogeneous) treatment of the nonhuman has always been ... about shoring up the human....

With good reason, ideas that suppress the similarities and stress the differences between animals and humans have come under scrutiny such that the conceptual divide is (becoming) far more flexible (cf. Arluke and Sanders 1996; Irvine 2007; Noske 1997a; Serpell 1986; Singer 1975). Attempts to highlight the commonalities between humans and animals are still met with suspicion. There is no reason to think the border between pets and nonpets is less inflexible or even less important. If Grizzly Man illustrates anything, it is that there is a powerful yet invisible boundary that arbitrarily separates pets from nonpet "others," whatever their form.

\section{Current Perspectives on Pet Animal Associations}

In order to appreciate petness as a relation, it important to examine the scholarship on pet animals that already exists. While most of the literature assumes that pets are animals, it can still provide insight as to how petness is constituted. The literature on pets focuses largely on two associated issues: defining a pet, and outlining why people keep pets. While the first subject bears significantly on the topic of this paper, generally those who address it explicitly tend to talk about pet animals in and of themselves and not about petness relationally. In order to distance myself from this, I will first examine the research that speaks to the topic of why people keep pets. This will frame my discussion of why the qualities generally used to distinguish pet animals from nonpet animals should not be seen as essential to their constitution. We must, instead, view them as composed through human emotion and relationships.

One of the key questions that has characterized theorizing and empirical research on pet animals centres on the subject of why they are kept. This provides insights into what pets are, but it is predominantly useful because its starting place is the relationship they have with humans. Generally those who speak to the question of why humans have pets imply the reasons are positive (Shell 1986). This appears to be a sensible presumption. Why would so many people live with and take care of animals if doing so was not worthwhile or rewarding? But we must not conflate keeping with loving, or assume that the emotional investment in pets is one of straightforward adoration. Plenty of research has pointed out this is often not the case. For instance, Kogan et al. (2004) recognize that ani- 
mals act as the conduit through which intimate violence against women is perpetrated. They explain that abusive partners regularly threaten or harm pets in order to control, hurt, or intimidate women and that concern for pets' safety often delays leaving abusive situations. Likewise, Flynn (2001) identifies a number of zoological crimes and cruel deeds that are regularly committed against animals, including those with whom humans share their lives. ${ }^{3}$

Certainly many pets are actively and immensely loved. Yet they may not be loved at all. They may be treated like possessions, as they are in Canadian law. They may be taunted, teased, ignored, neglected, or cruelly abused. Pets seem to exist in a strange state where they can be loved ones, family members, friends, throwaways, companions, sources of support, objects of frustration, pests, nuisances, or victims (Shell 1986). In short, they are objects of ambivalent emotions and treatment, which makes identifying one foundational quality of petness difficult.

Although the exploitative treatment mentioned above might seem at odds with caring and nurturing behaviour typically associated with pets, Tuan (1984) explains how such varied emotional and physical conduct can coexist in our interaction with pets. Tuan claims humans derive great pleasure in exercising power, particularly over nature. While he recognizes this is often manifested in overt acts of exploitation or brutality, he also believes we can satisfy the desire to dominate or master others through more benign actions, most notably, affectionate, paternalistic ones. Accordingly, Tuan argues our adoration for pets is one way humans exert control. This makes endearment inseparable from dominance. He writes:

Affection mitigates domination, making it softer and more acceptable, but affection itself is possible only in relationships of inequality. It is the warm and superior feeling one has toward things that one can care for and patronize. (1984:5)

To be sure, the relationship between humans and animals, especially those with which we reside, is necessarily imbalanced. We are animals' stewards; we control what they eat, where they go, where and when they

3. Flynn's argument applies to all animals, not just those characterized as pets. Most importantly, he attempts to challenge predominant notions of what cruelty means when applied more broadly. Flynn argues that while humans consistently mistreat animals, only under certain circumstances (for instance, when visited upon pets) are such acts deemed malicious and wrong. This is because callous behaviour only represents actions that are outside of socially acceptable boundaries, which can therefore only happen to particular animals. Such practices as killing animals for meat, hunting them, using them for scientific research, and a host of other "border cases" (which depend on the time and context) do not count as cruelty because they are customary and accepted. 
urinate and defecate, whether they reproduce, and so on. We even train them to behave and induce them to play or perform tricks for our amusement. Affection toward pets then, should not be considered in opposition to dominance. Rather, it simply should be regarded as its softer side.

For Tuan, equal interspecies love appears impossible because petness is underscored by the human ability to manage others, both physically and representationally. Surely this aspect of petness should not be ignored. We must accept that dominance is always a possibility in petness, whether its expression is tied to caring or violence. However, it is also too narrow to be the fundamental feature. For instance, Tuan characterizes pets as "diminished beings" or "personal belongings ... that one can take delight in, play with, or set aside, as one wishes" (1984:141). This portrayal seems to overlook the significant place pet animals have in humans' lives. Although it is true that many pets are treated cruelly, a large number are not. Many pets are more than small playthings we engage with recreationally, but are close companions with whom we share our time, energy, love, and lives (Irvine 2004b). It would be careless to reduce these feelings merely to a latent desire to dominate, especially since what might be termed "equal" relationships between humans also display such tensions and exceptions. Smith (2003) insists that the dominance/affection model is an inadequate framework for discussing pet-human relationships because it is always there, always possible, and unavoidably ignores the ways in which humans attempt to cope with their power and to relate to animals in a more egalitarian manner. Above all, she criticizes this model as missing critical points regarding the daily interactions between animals and their human companions, which involve reciprocal interaction and negotiation. Dominance/affection characterizes pets as entirely submissive, obedient, and without any agency even though many both people's and animals' day-to-day experiences suggest otherwise.

Ultimately whether dominance is seen as endemic to, or in conflict with affection, most theorists accept that humans are drawn to pets. Some authors claim that biological factors account for our connection with animals. I doubt such explanations fully account for the vast array of reasons people have pets and I recognize that claims rooted in biology or genetics have the dubious characteristic of fostering essentialism. But they do impress upon us that biological capacities influence our (putatively exclusive) social relations. For that reason, it is worth recognizing there are a few types of animals, particularly cats and dogs, which may be popular, in part, because of their characteristics. In examining the rise of pet keeping, Serpell (1986) wonders what made small carnivores appealing companions, and offers several reasons for their attractiveness. 
To begin with, he appreciates that the domestication of dogs and cats is an accident of history driven by the coalescence of harmonious forces, which include elements of their species-specific dispositions. They're not too large or too small, do not need to be caged continuously, are not overly or indiscriminately violent, and "like" to be around humans because they are either highly social (dogs) or because they are tied to certain territories (cats). He further notes that they were likely useful for keeping away pests or doing other important work, which helped to foster more affective relationships. Kruuk believes that cats and dogs are more suitable as companions than other animals for several critical reasons (2002:144). They impose few limitations on humans' lives since they are only active for a few hours each day. They are also highly intelligent, adaptable, and readily trained. These animals can fit in to humans' lives and dwellings, whatever shape they take, quite easily.

While such speculation may provide some insights into how animals emerged as widespread household companions, it does little to actually explain contemporary relationships between animals and humans whereby pets are bred, sought out, live luxuriously, and are of little or no instrumental utility (Nast 2006). Other authors recognize that pets today are generally "useless" economically and instead contend that their appeal lies in more sentimental and visceral factors. Wilson (1984) certainly adopts this perspective. He argues that biological processes compel humans toward a love of nature, calling this phenomenon, biophilia. $\mathrm{He}$ claims that there is an instinctive bond between humans and other living entities, particularly animals. This can help account for why humans keep pets, and also engage in a whole host of other behaviours, including such mundane practices as tending gardens, taking hikes, going to zoos, etc. In his view, our love for life forms and our desire to be around them is natural and may even serve evolutionary purposes. Serpell (1986) acknowledges this as a distinct possibility in accounts of pet ownership. He argues that pet keeping is habitually deemed a silly aberration because it seems to serve no recognizable purpose. However, he wonders whether humans are generally predisposed to love other creatures and if cruel and exploitative treatment is the deviation that has slowly become accepted through processes of rationalization. Again, claims about humans' or animals' biological dispositions must be met with caution and understood only in the context of a given society. For instance, Wilson's recognition of humans' love for the natural world may not be instinctual, but rather a simple reaction to seemingly endless urbanization or a feature of humans' increasing concern for an environment under threat.

Romantic understandings of human pet relationships are not the only ones influenced by evolutionary theory. Archer (1997) maintains that the 
combination of humans' and animals' innate qualities is responsible for pet ownership. In his opinion, pet-human relationships are difficult to understand because attachment and devoting resources to another species are fitness-reducing activities, at least in theory. Nevertheless, humans are highly attached. He argues this is because pets manipulate responses that have evolved to facilitate human relationships, particularly between children and parents. He claims: "the initial appeal of the pet arouses the owner's interest and sets off the subsequent train of interactions" (1997:251). This appeal is found in pet animals' neonatal physical characteristics: their proportionally large heads, big circular eyes, soft fur, seeming astonishment at small wonders, spontaneous and inquisitive character, and so on (Hart 2003). Archer describes pets' relationships with humans as parasitic since they exploit innate human tendencies to care for and nurture young humans. He accepts that pets serve an emotional purpose and provide love and companionship to people (whether real or perceived), but he doubts whether this role compensates for the resources they use.

The company and affection provided by pet animals are doubtless the most recognized of their qualities. Many researchers have wondered whether there is a link between these qualities and pets' ability to improve health, well being, and the quality of humans' lives. While the data on the health effects of pet ownership do not paint a consistent picture, Siegal (1993) claims that most studies demonstrate some mental or physical health advantage to the practice. In her own work, Siegal is most interested in the link between attachment and stress reduction. She argues that people learn to become attached to pet animals because they consistently provide positive responses. Their association with feeling good, wanted, and so on, "leads the owner to view the animal as a source of comfort" (1993:163). Accordingly, pets provide security and reassurance, which decrease people's anxiety, reduce stress, and therefore, may improve health. Others have focused on the immediate physical benefits of owning pets. For instance, Friedmann et al. (1980) found that pet ownership increased one's chances of surviving a heart attack by over $20 \%$. Most notably, other factors, such as whether patients were married, did not produce significant results. Pets enhanced the recovery of their owners irrespective of the severity of the original heart attack. Katcher et al. (1983) linked watching fish in aquariums with a reduction in blood pressure, most markedly among people suffering from hypertension. McNicholas et al. (2005:1252) observe that pet ownership has been associated with lower use of medical services and a reduced risk of cardiovascular disease, to name a few benefits. It is no wonder that pet-assisted therapy and companion animal visitation programs are ballooning across 
North America. It appears that the links between pet companionship and human health or happiness underscore the reality that pets make most people happy.

In spite of these conclusions, most researchers remark that pets are not principally valued for their role in health improvement. Rather, they are appreciated for the companionship they offer for its own sake. In the main, pet animals are viewed as humans' friends, which is evident in their treatment throughout life and upon death. Many pets are indulged with a variety of specialty foods, toys, medicine, clothing, and other accessories intended to improve their quality of life. People who lose their pets often experience immense sadness, grief, or even depression. Deceased pets are given funerals (even beside the toilet bowl for pet fish) or graves with markers bearing special messages (Shell 1986:122). These feelings represent a key component of petness. Still, such responses to pet death do not quite capture what pets "are." For instance, people seem to love and even mourn the passing of animals in zoos, marine parks, or in the wild. Should these animals count as pets? Outlining the way pets have been defined by others shows there is no basis for insisting these, and any other creatures, should be not count as pets. Inevitably, the problem with trying to characterize or classify pets, per se, is that we miss the critical point that they can't be classified. We can only outline the practices that constitute entities and relationships.

Although many scholars conduct research on human-pet relationships without really addressing what pets are, others have attempted to tackle this tricky matter and define pets. However, most of the presumed characteristics that supposedly differentiate pets from nonpets do not hold up under scrutiny. Pets have no essential characteristics and they are solely created by humans' view and conduct toward them. This is likely the reason there is no agreed upon definition of what makes an animal a pet - there are simply too many traits that both pets and nonpets possess. Some of the commonly noted qualities and attendant definitions are worth mentioning, if only to emphasize the point that we must look at relations, and not objects' essences.

Likely one of the most popular properties that purportedly distinguishes pets from other animals is their status as nonfood entities. This is not to say that any one animal is universally recognized as a pet protected from consumption. The pets of one region may be the dietary staples of another. Instead, pets are seen to be animals that are never eaten. Serpell (1986:53-55) summarizes some of the key reasons pets are nonfood entities, and suggests that the taboo is linked to proximity. For instance, he notes that some authors claim consuming a pet is symbolically associated with the sexual intercourse between close relatives. Others argue 
that pet animals are seen to resemble humans too closely. Belk (1996) remarks that competing metaphors whereby animals vacillate between the human civilized world and the chaotic animalistic one make pets indeterminates. Thus, eating them would be too close to a form of cannibalism. While the idea of eating a beloved pet cat may be sickening, according to Lawrence (2003) this boundary far from rigid. For instance, she points to school programs where children raise farm animals, and in effect deem them pets. Yet these animals eventually will be sold for slaughter and eaten. It is also quite common for people to nurture their future dinners. Noske (1997b) points out that the practice of protecting or coddling and caring for animals intended as food is ordinary among some pastoralists in Africa, while Wright (2004) documents similar behaviour in farmers in the American Midwest. Animals' statuses and destinies have also been known to change quite rapidly depending on the circumstances. ${ }^{4}$

Even if we cannot completely distinguish pets from nonfood animals, others have provided some insight into how pets can be identified. Eddy (2003a:100) explores some dictionary definitions to provide perspective. He notes that the word pet means either: "a domesticated animal kept for pleasure rather than utility"; or "a) a pampered and usually spoiled child or b) a person who is treated with unusual kindness or consideration." In his view, the former definition is problematic for several reasons. For one thing, many pet animals work and provide income. They may be bred and their offspring sold, raced, used in hunting, on farms, in therapeutic settings, and so on. Moreover, the idea of being domesticated is quite vague. Generally it refers to the phenomenon whereby life forms are adapted to live under human influence. Rollin and Rollin (2003:107) say that domestication is no longer accepted as a specification of petness since it is an ambiguous term that generates unnecessary and distracting questions. However, they do suggest that pets are at least domestic, which is a geographic reference meant to capture animals' living conditions. Pets are seen as residing with or in close proximity to humans and in this respect differ from wild, captive, food and working animals. Ultimately, Eddy (2003a:103) rejects this outlook, instead defining pets as "animals who are treated with unusual kindness or consideration." In his opinion, this definition is advantageous since:

...it stresses the amicable view held by the person for the animals, it remains silent on the function to which the animal was (or will be) put, and the source of the animal has no bearing on its status as a pet.... In a sense,

4. To some degree these examples do not really speak to the idea of eating pets. It might be entirely different to take on an animal as a companion and subsequently eat it than to care for an animal that, at birth, is known to be food. Nevertheless, the cases at least illustrate that the boundary is far from rigid. 
the adoption of this definition results in a greater focus on the humans involved in the human-pet relations, and places less of an emphasis on any intrinsic or extrinsic properties of the animals themselves (2003a:103).

Eddy recognizes that animals in zoos, aquariums, or other locations can be pets and that it is the relationship that should be central. His ideas speak to my position that it is relations that make petness.

Unfortunately Eddy fails to provide a completely relational perspective, and therefore, his analysis suffers from some problems. Notably, his definition remains invested in objects and not relations (Eddy 2003a; 2003b). He overtly defines pets as animals and the qualification of "unusual kindness" is ambiguous. Treating something with unusual kindness suggests that the treatment is remarkable. Even if there is an implicit contrast between pet and nonpet animals, how could roughly 50 million typical pets, as well as the other entities he wants included in the category, all be treated remarkably? Rather than being remarkable, such treatment is actually quite ordinary. More importantly, some animals that are clearly pets get excluded - those that are abused or treated cruelly (Rollin and Rollin 2003:107). Petness often includes positive emotional interaction and affection, yet as mentioned, it is underscored by the possibility of domination, which may be expressed in acts that are clearly malicious, exploitative, and punishing (Tuan 1984). Eddy was further criticized by Rollin and Rollin for neglecting to offer a precise definition of pets that "encompasses all things that we ordinarily call pets, and only those things that we ordinarily call pets" (2003:110). In breaking from their view, I think that particular contribution represents both the beauty and obstacle in investigating petness: it offers possibilities but may defy convention. Sanders (2003:115) puts it this way:

it is more productive to acquire an understanding of the reality of the phenomenon as it is defined by the social actors in whom we are interested.... Approaching the issue of what is a pet, how this designation is understood, and how people use an animal's 'pethood' to shape interaction moves us outside of the constraints of viewing the pet as an 'object' in the world of obdurate reality into a more rich, flexible and often ambivalent realm of subjective definitions that people use to shape, understand and experience their relationships with their nonhuman coactors.

Sanders' stance allows us to investigate what qualities make entities worthy of humans' attention and devotion as pets without requiring that any of them be present. Overall, the point should not be that any particular creature cannot be included, but rather, that any one can. 


\section{Petness in the Inanimate}

While petness in nonliving things has been overlooked by most academics, in the last decade there has been a proliferation of virtual pets. What were once simple computerized devices that responded in predictable and highly structured ways are now sophisticated entities that vary considerably in their make up and capabilities. These virtual, cyber, robotic, and artificial pets comprise a multibillion dollar industry that spans both the material and the online world, and covers everything from virtual keychain, robotic, and plush pets, to online, wireless/cell phone, and CDrom pets. The flourishing industry, and the millions of people worldwide who engage with these technologies, have not gone unnoticed. Aside from business analysts, a handful of people working in the fields of technology and mental health have attempted to understand the place and utility of these pets. Some of this work is striking because it recognizes that virtual pets serve an emotional purpose. In fact, the parallels between animal pets and object pets have been drawn overtly. However, this point needs further exploration. The problem is that pet objects are seen as akin to pet animals, but not as true pets in their own right.

As mentioned, there are a range of different inanimate pet objects available on today's market, but it is likely that many readers do not know what they are or what they do. To some degree, this is because many of these products are most popular among children and teenagers. The most fashionable of the virtual pets are the material ones: Tamagotchis, Furbies, Aibos (or similar competitors, NeCoRo, Tama, and PARO). Bandai's keychain pet, the Tamagotchi, was the first of the virtual pets introduced in recent years. Tamagotchis were originally conceived by a Japanese mother for her children who could not own an animal because of limited living space (Bloch and Lemish 1999:284). This virtual pet is a tiny creature from another planet that lives in a hand-held liquid screen enclosed in a plastic egg-shaped covering with a number of tiny push-buttons on it. Once the game is turned on, the pet is hatched (born), the name, birthdate, "sex" and time are recorded, and owners take on the responsibility of raising "it." In order to sustain the pets, owners must engage with them regularly. Tamagotchis require ongoing and balanced care, which is indicated by an alarm and icon that appears on the screen. To ensure they become happy and healthy, owners must provide such necessities as food, drink, clothing, medication, exercise, play, toilet flushing, teaching, and praising, which can each be dispensed at the touch of a button. Owners should even turn out Tamagotchis' lights when they go to sleep. However, sometimes Tamagotchis will refuse owners' intrusions, at which time they require scolding. At any point an owner 
can also assess the Tamagotchi's progress and identify its needs, looking at the age, weight (they can become overweight!), amount of training, and level of happiness and hunger. Tamagotchis that are ignored can get sick or die quickly, and then a new one will hatch, although this was not always the case. Otherwise the lifespan is generally a few weeks. In the third version, released in 2005, more than one pet can live within one egg at the same time, Tamagotchis will marry and bear offspring, and Tamagotchis can communicate and share with each other. To keep pets happy, owners also need to visit "Tamatown" online to visit relatives, play games, and purchase luxurious "Gotchi-Items," including clothes, leisure items, specialty food, travel, and other accessories. Tamagotchis require involvement, and taking care of them requires commercial expenditure, forethought, and dedication.

Mival et al. (2004) argue that Tamagotchis spawned the virtual pet craze and led to the creation of other virtual pets, including Furbies and more "realistic" Aibos. Hasbro's Furby differs from the Tamagotchi in that it is a plush automated bird-like creature whose actions and reactions are initiated through a series of sensors that respond to light, touch, sound, and movement in the surrounding environment. Furbies are said to possess a number of sentiments that can be communicated through verbal expressions of clicking, chirping, singing, and some limited speech. More significantly, Furbies are able to move their eyes, beaks, ears, and bodies to communicate nonverbally. These "emoto-tonics" give the Furby a number of recognizable emotional expressions including, happiness, sleepiness, surprise, fear, sadness, and so on. Furbies can also communicate and interact with each other, and in so doing, appear to play cheerfully. Another notable characteristic of the Furby is that it cannot be shut off without removing its batteries. Attempts at putting it away are met with resistance and claims such as "me scared" or crying. Eventually, the Furby will go to sleep, but it is easily reawakened with stimulation. In this sense, furbies function as intelligent and expressive beings.

Sony's Aibo (Artifical Intelligence RoBOt) is also a larger toy pet, but is hard plastic and shaped like a small living dog. The Aibo's functionality is similar to a Furby's, but it is also able to walk around and can respond to roughly 100 spoken commands, much like a dog. It is able to "see" through a camera on its head, and can therefore navigate its physical surroundings and search out items. It will even walk to its recharger. However, the most captivating aspect of the Aibo is its fastidiousness (Mival et al. 2004:3). It is able to learn tricks and play with its owner, yet may refuse to do so for no real reason. It can also convey displeasure if annoyed or ignored, will refuse to interact or perform 
tricks correctly, and can even change its posture to reflect its mood. Most interestingly, the Aibo will slowly become more agreeable over time to reflect development into adulthood.

There are also a number of virtual pet websites that allow you to adopt and subsequently take care of creatures over the internet. These include Neopets.com, Marapets.com, PowerPets.com, AdoptMe.com, and Webkinz, the latter which spans the material and virtual worlds, to name a few types. With the exception of the second last example, which allows individuals to adopt virtual animals that bear the likeness of real biological creatures (dogs, horses, snakes, etc.), the other sites feature more magical simulations of assorted species, both real and imagined. Each of these sites resembles Tamagotchi in that the purpose is to keep the pet happy and healthy and to foster development. The process is far more elaborate since these entities exist in their own large and complex worlds where the possibilities for entertainment and engagement are endless. In the case of Neopets, the most popular of the cyberpets, you can create a new pet or adopt one that has been abandoned at the adoption centre. ${ }^{5}$ Individuals can pick from a number of dispositions, choose a sex, a name, and create a description of the pet's character. Of course, the pet has a variety of needs. It requires food, toys, accommodation, game-playing, medicine, pets of its own, and so on, all of which come at a cost. Owners can earn the requisite "neopoints" to pay for such items by playing one of hundreds of games, signing up for surveys, getting jobs, and if all else fails, looking for the range of giveaways available throughout the world of Neopia. Neopets also resemble Tamagotchis in the way they make requests, demands, and express emotions, in particular, directly conveying sentiment toward the owner. However, in contrast with the physical virtual pets, Neopets act as the medium through which individuals are able to play a larger game. Individuals' Neopets can battle each other or preprogrammed opponents. In order to battle competitively, they need training, equipment, and special powers, which can be costly. Individuals can also complete one of the many secret explorations or various quests available. All of this further advances the pet and the number of possibilities within Neopia for the pet's existence.

These entities are unique and part of the way in which they are constituted as pets arises from their intrinsic capabilities, which differ from more conventional toys. For example, virtual pets are much like dolls and stuffed animals in that they are the objects of affection and nurturance. However, Bloch and Lemish (1999) point out that while both

5. According to Alexa.com, an independent rating site that measures internet traffic, neopets.com is among the top 150-160 most visited websites worldwide. Neopets.com claims over 70 million virtual pet owners worldwide. 
stuffed toys and virtual pets can be cared for, the former engage solely through humans' imagination. Even somewhat physically interactive dolls (those that need to be fed or have their diapers changed) are generally unable to engage verbally. They impose materially, but are unable to make serious spontaneous requests. By contrast, cyberpets demand what they need while supplying the means by which to provide it (Bloch and Lemish 1999:289). Thus, despite the profound differences between various cyberpets, Marti et al. claim they all "share key behaviors: they act autonomously, they require frequent interaction and they develop in response to their owner's actions" (2005:100). Virtual pets are responsive and connect with owners in ways that are both structured and spontaneous; they relate with and impose upon humans outside owners' intentions. Dautenhahn (n.d.:5) claims that interactivity is the critical element that makes cyberpets so believable and popular, and can even compensate for simple and unrealistic design. Even though most of their needs are easily anticipated, pets' input makes them more than simply toys or the objects of behavioural management, as Kritt (2000:85) asserts. What links them all is their common "useful uselessness" as companions (Mival et al. 2004).

McCallum (n.d.) argues that their general appeal lies in their status as both living creatures and learning devices that generate enjoyable symbiosis. Owners care for their pets, and in return, pets remain happy, behave obediently, return affection, and thrive. In their design, cyberpets explicitly provoke a caring response from users, and attachment to pets can become remarkably intense. For example, there are a large number of virtual temples and graveyards dedicated to "dead" pets, mainly Tamagotchis, and bullies have been known to intentionally "murder" others' unattended pets by "feeding them excessively and choking them to death" (Zizek 1998:144). Bereaved owners write messages, poems, songs, and obituaries expressing their love and sorrow for their adored deceased companions. There are also virtual funerals and internet burial sites where grieving people receive comfort from others who understand their loss (Bloch and Lemish 1999:286). In other words, individuals come together to mourn the passing of a loved one, despite the fact that most Tamagotchis only live for a brief time. In some cases, people have even committed suicide, had nervous breakdowns, or become clinically depressed following the death of their virtual pet (Mival et al. 2004:2; Zizek 1998:144). Surely this confirms Wu and Miller's suspicion (2005) that owners form genuine emotional bonds with their robotic pets.

Virtual pets are programmed to imitate both human and nonhuman sentient beings. But the effectiveness of their configuration, and their attendant petness, lies in the way humans experience them. Dautenhahn 
claims believability is responsible for their popularity. Believable technology is familiar to humans; it meets their needs intellectually, emotionally and socially. Virtual pets

look 'alive' because they show behaviours which are typical of animals [and humans]: paying attention, playing, social behaviour, etc. These are all 'entry points' which allow the observer to match the artifact's actions with behaviour which is shown by living systems. (n.d.:3)

It is through interactions and the ascription of certain traits that toys, like animals, become pets. Rational or not, owners feel emotionally attached to their pets and even experience these entities as animate. They attribute intentioned aims to them. Kahn et al. (2006) found that virtual pets' responsiveness generated unique treatment and handling. They observed that while young children had similar evaluations of a stuffed dog and an Aibo, their behaviour toward each was noticeably different. For instance, they were far more inquisitive and reciprocal toward the Aibo, and even showed some apprehension (flinching) when it moved. To the researchers, this suggested that minimal social cues can generate social responses, even when the items are known to be artificial. Indeed, this is a critical difference between pets and toys, games or hobby items. Whereas these latter three objects may be played, enjoyed, or fiddled with, petness is characteristic of objects that play or act back and generate meaningful social contact.

Caporael (1986:215) recognizes such reactions as anthropomorphism: "the ascription of human characteristics to nonhuman entities." In his opinion, the personification of inanimate objects is widespread and yet largely ignored in modern life. Nevertheless, he suggests it serves the important function of bringing these entities into the social world. He further explains,

many people have entrenched, coaxed and threatened a recalcitrant car, have inferred human feelings and motivations as causal explanations for otherwise inexplicable malfunctioning, and in short, entered (briefly or extensively) into social relations with their automobiles. Anthropomorphized, even unintelligent machines become social entities.

Other researchers acknowledge that anthropomorphism is overt in humans' dealings with such machines as virtual pets. Research conducted by Marti et al. (2005) among children with severe cognitive impairments found explicit reference to a robotic seal's emotional state. They "recognized" such feelings as sadness, anger, and even happiness in the robotic pet (2005:105). Even research among adults suggests that anthropomorphism is an important quality. Wu and Miller's study (2005) with 
elderly individuals illustrated that human-like interaction is an important feature for assistive technologies. Those in the study reported that their decision to respond positively was directly affected by the technology's capacity to be "polite" and to have a positive and natural personality. What is important in each of these studies is that machines become individuals with which people engage on a more intimate level. Each of the aforementioned authors largely reifies the belief that action and emotion are the territory of the human. Their assertions nevertheless imply that anthropomorphism is more than a psychological mechanism since the focus is on social action and reaction.

Latour (1988a) is also critical of the view, largely endorsed by sociologists, that anthropomorphism is a misguided mental "projection" of human behaviour or feeling onto nonhuman objects. He argues that there are no singularly human qualities; inanimate objects always possess the qualities and do the work credited to humans. In this way, living and nonliving things are already mutually (re)active since "“anthropos' and 'morphos' together mean either what has human shape or what gives shape to humans" (1988a:303). This latter meaning has largely been eclipsed by the former, but it is critical in understanding the essentially social, not psychological, nature of anthropomorphism. In the case of virtual pets, we must recognize that they are more than machines to which we ascribe human or animal characteristics through mental processes. In their being, virtual pets operate and are experienced as life-like entities. We respond to them, and they to us. As Dautenhahn (n.d.:5) puts it:

what makes cyberpets special is the fact that they exhibit interesting behaviours only in the interaction space of agent and user. Social bonding cannot be generated by the agent, or user alone. But by agent and user interacting with each other, new forms of interesting behaviours on a different level of complexity can emerge.

Virtual pets and their owners are co-constituted in social reciprocation. Anthropomorphism and its simultaneous partner, "morphoanthropism", 6 imply mutuality - not necessarily in intention (although Latour's example of the inanimate door closer "on strike" diminishes this qualification) - but certainly in action and outcome (1988a:303). Anthropomorphism is inherently social because inanimates manipulate, and are manipulated by, humans. For Dautenhahn,

cyberpets are examples of how humans view and interact with the (social)

6. Morphoanthropism is my term. I use it to highlight the different and noteworthy definition generated by placing "morphos" in front of "anthros" to mean what gives shape to humans. 
world, how they are biased to interpret the world in terms of intentionality, and how much humans need the feeling of belonging and being engaged with the world. (n.d.:6-7; italics mine, parentheses in original)

This serves to demonstrate that inanimate objects need to be taken more seriously as participants in the social world. Certainly they are not inherently so. More importantly, they are also not pets by reason of some shorthanded parallel. Inanimate and virtual pets are not virtually pets or "like" pets; they are, simply, pets.

\section{Petness and the Sociological Imagination}

I have illustrated why petness is an important concept that highlights the relations that generate pet objects. My discussion has largely focused on the importance of pets or petness to individuals, thereby emphasizing the more psychological processes and effects of engaging with animal and digital others. But sociological concerns are eminently different from psychological ones in that the sociologist, broadly speaking, studies the social dynamics of modern society. For my purposes, it is worth considering the way in which petness relates to other social forces. For instance, why are the number and diversity of pets increasing? How can we understand petness with regard to larger social processes? What sorts of forces underlie this growing trend? These are important questions if the idea of virtual pets is a coherent one, as I believe it is.

Anthony Giddens (1991) offers some insight in this respect. He argues the focus of existence is increasingly upon processes of selfactualization, and that people's choices become a means of expressing self-identity. Yet this is always changing and is "something that has to be routinely created and sustained in the reflexive activities of the individual" (1991:52). However, Giddens claims such reflexivity is a key feature of both sexual and platonic interpersonal relationships. This is because they have transformed into what he terms "pure relationships." The pure relationship (1991:87-97) centres on trust, commitment, and intimacy, instead of obligations stemming from external economic or social-cultural forces. It is sought simply for the satisfaction closeness with another can offer, "unprompted by other than the rewards that the relationship provides" (1991:90). More than this, he claims the pure relationship is "prototypical of the new spheres of personal life" insofar as it also requires continuous reflection and work (1991:6).

Giddens' notion of the pure relationship suggests mutual activity on the part of self-conscious subjects since intimacy requires individuals constantly assess their status in relation to others. Accordingly, the self 
can be amplified and secured by the relationship, but also exposed to existential anxiety. This is because intimacy is predicated on trust, which is linked to "achieving a sense of ontological security." He continues:

trust in this sense is basic to a 'protective cocoon' which stands guard over the self in its dealings with everyday reality. It 'brackets out' potential occurrences which, were the individual seriously to contemplate them, would produce a paralysis of the will, or feelings of engulfment. (1991:3)

While relationships with other people may offer support and pleasure, they may also cause apprehension or distress. Perhaps pet relations are important because they offer the former without the latter insofar as individuals feel unconditionally cared for by their pets. For instance, Serpell doubts that animals can be true friends in the way other people can. Nonetheless, he agrees that their company "enhances self-esteem and a sense of personal worth" (1989:127). Pets allow us to invest emotionally in another while often (but not always) giving us the impression that our sentiment is reciprocated. In other words, pet relations share the contours of purity in the sense that the relationship is sought for its own sake and is rewarding because the pets for whom we care, regardless of their form, seemingly appreciate our attention and even care back.

While pet relations may be characterized as pure in the sense meant by Giddens, others focus on the commodification of intimacy as it is manifested in virtual pets. Bloch and Lemish (1999) argue the rapid popularization and subsequent passing of the Tamagotchi fad is indicative of a problem underlying the character of interpersonal relationships in consumer culture. Employing a neo-Weberian analysis to the case of Tamagotchis, they suggest attachments increasingly lack nurturance, patience, mutuality, and empathy. They argue the Tamagotchi itself, and the consequent bond made with it, embodies the four main dimensions of modern rationalization. This is because Tamagotchis, unlike other people or animate pets, require minimal care and offer nothing that is unstructured or unscripted. They explain:

Tamagotchi is efficient, providing an effective method of meeting a variety of needs, in its capacity for satisfying the desire to provide care, such as for a pet, while incurring no ongoing expenses and employing minimal space. [It] offers calculability, where quantity and speed are emphasized over quality or personal satisfaction, in its development pattern and through its ability to be reborn, repeatedly and identically. Predictability, whereby events are predetermined and offers no surprises, is manifest in the Tamagotchi through its preprogramming. Finally, control, in which events are determined by nonhuman technology, is precisely what one side of the interaction with the Tamagotchi entails (1999:291). 
These interactions are not based on a desire for true emotional contact or engagement, but represent an end run on forming rich and involving associations. They argue that relationships with virtual pets involve only "para-social" or "unidirectional" interaction since these entities lack individual personalities with which we engage reciprocally and merely fill the empty role of a dependent (1999:293). In sum, they claim our relationships with virtual pets are trivial, fleeting, and disposable, thereby reducing attachments to those of means and ends.

Similarly, Zizek (1998) characterizes the relationship between humans and Tamagotchis as inherently perverse and problematic. Notably, he challenges the notion that virtual pets should be characterized as interactive, suggesting instead that they are the "ultimate example of "interpassivity" (1998:143). Interpassivity refers to a way of relating to others in which an active subject reacts to a passive object. It places people in a position to respond to others' actions and behaviours, where the activity of one person or thing allows for the passivity of another. Yet in truly interactive relationships, the active and passive roles are dynamic and changing whereas in interpassive ones, things are done "not ... to achieve something, but to prevent something from really happening, really changing" (Zizek 2002:170). Pelletier (2005:318) observes that

interactivity and interpassivity are mutually constitutive. Interactivity allows me to be passive while being active through another (for example, pressing buttons translates into in-game actions); through interpassivity, I am active while being passive through another (I fulfill the game's demands).

Zizek (1998:143) offers some examples of interpassivity, including the Greek chorus or modern television's “canned laughter" tracks. In both cases, the entirety of spectators' emotional experiences are taken over and articulated for them. Likewise, with virtual pets, people feel the appropriate emotions, but only because signals emitted from the pets make demands upon us. In this way, the Tamagotchi is not only the wholly active entity in the relationship, it has reduced emotion to the symbolic level, replacing altruistic compassion with a private, idiosyncratic egotism, all the while blurring the boundary between the two (1998:145).

Zizek also stresses that interpassivity extends beyond individual relationships. Interpassivity is the process whereby people's actions are appropriated so they become only responsive. This means that others do our work for us, and in this case, the work is emotional in character. Zizek states:

tamagochi [sic] is a machine which allows you to satisfy your need to love 
thy neighbour: you have a need to indulge in care for your neighbour, a child, a pet? No problem: tamagochis enable you to do it without bothering your actual neighbours with your intrusive compassion. (1998:145).

When we act toward virtual pets (by feeding, playing, etc.), we are not truly agents. Rather, we are acting through another even while our passivity in the contact is invisible. Our only enjoyment is the Tamagotchi's. In other words, Tamagotchis give us the appearance of interaction, but really there is no dynamic engagement. In many ways then, the Tamagotchi mirrors our larger existence because interpassivity is empty activity where we do things that are ultimately self-referential, to either the self or larger extant ideology, which maintains the status quo of capitalism (Zizek 2002). As Zizek puts it (1998:146):

perhaps therein resides the ultimate cause of tamagochi's success: it provides the best metaphor for what is fundamentally false and sterile in the frenetic activity in which we are caught in our daily lives.

For Zizek (1998) and Bloch and Lemish (1999), virtual pets triumphantly exemplify the success of consumer capitalism where relationships are transitory and emptied of genuine consideration for the other. In both works the economic imperative becomes hidden in the background of adoration and affect. Interestingly, they both also explicitly distinguish virtual pets from animate pets. Their condemnation of virtual pets (Tamagotchis specifically) is made by way of comparison with organic creatures, thus suggesting that contact with the latter is different, more acceptable, or better than with the former. But what makes virtual pets uniquely awful? Why are pet animals in these intimations revered and personified more than ever; elevated almost to the level of the human? In my view, neither piece makes a particularly strong case for condemning virtual pets. Virtual pets have become the proverbial scapegoats of their larger complaints with the trajectory of interpersonal life in what Bauman (2003) has termed, "liquid modernity." Their contention that humans' relationships with virtual pets are trivial, empty, and somehow take the place of more profound ones ironically rehashes old discredited criticisms leveled at the human-pet animal relationship (Serpell 1986). It seems many worry about undermining a venerated sociality between humans that never really existed in the first place (Latour 1988b).

What both pieces really seem to address are processes of alienation where humans' powers are experienced as forces emanating from an objectified externality or where (hyper-reflexive) human emotion is exploited for capitalist means (Hochschild 1983; Marx 1977). Zizek would probably agree with these conclusions. Yet juxtaposing virtual pets with 
"real" pets makes this inference uncertain. It should not be problematic or incoherent to associate love and nurturance with digital and electronic products. If we cannot do this, are we not privileging the natural over the mechanistic with attention on such features as preprogrammed responses, the origin of instigation, the privatization of sentiment, and the simplification or simulation of emotion? We must begin to rethink what we mean by sociality and the ways it is tied to love, isolation, power, economic interests, and so on. Knorr-Cetina (1997) warns that we need to move away from our fixation with humancentric models of connection. She writes:

the untying of identities has been accompanied by the expansion of object-centered environments which situate and stabilize selves, define individual identity just as much as communities or families used to do, and which promote ... social forms of binding self and other that feed on and supplement the human forms of sociality studied by social scientists. (1997:1)

While her focus is on objects of knowledge and expertise, it is nonetheless applicable to my study of petness because it helps us reconsider how we can problematize categories. Again, the focus must be on the human dimension of feeling, which means relationships with pet animals are no more important than those with virtual pets, or those between humans more important than with animals, for that matter. And ultimately, the commodification of love or intimacy has little to do with these qualities.

\section{On Petness: Limitations and Directions for Future Work}

It may seem alarming to suggest we can talk about Tamagotchis and cats equally as products of the investment of human emotion into objects. Similarly, a focus on relations among humans, animals, and machines may be seen as minimizing or ridiculing the profound devotion and love many people feel for their pet animals. This paper may have even been dismissed as but another piece in the anthropocentric-speciesist canon because I neglect the subjectivity of animals. These responses are understandable, and require some consideration.

My argument is anthropocentric since it proposes we can or should talk about animals and other things in terms of their relationship to humans. I am admittedly guilty of what Sanders and Arluke identify as a rather restricted approach to studying animal-human relations that

has sought to capture the perspectives of the humans who interact with or think about animals ... [without] any attempt to capture the perspectives 
of the animals themselves. (1993:378)

However, this anthropocentricity arises because I destabilize pets as simply objects and instead identify them as objects of sentiment; socially constructed entities defined through interaction. Everyone would/should agree that both pets and nonpets exist, even if the basis for categorizing them is contested. But how can we talk about the human perspectives and practices that generate these particular creatures without implicating the human-centred process by which this is done? We simply cannot ignore the fact that animals' destinies are largely the outcome of humans' impulses, even if we do not agree with this. Consequently, I find myself challenged to find another way to talk about petness in terms that are, at the same time, neither essentialist nor anthropocentric. To my mind, the former is possible while the latter is not; this project is fundamentally different from the intersubjective empirical research Sanders and Arluke advocate.

Despite this paper's anthropocentrism, it is not speciesist. Definitions vary, but generally the term refers to assigning different rights or values to beings on the basis of their belonging to different biological species. Noske (1997b:189) further adds that speciesism is a prejudice that eclipses individual distinctiveness. Again, pointing out that pets exist and are predominantly nonhuman animals, but also other things, is not a speciesist attitude. In addition, accounting for the socially constructed relation of petness is an attempt to explore the way in which entities become the focus of personal human interest. One of the salient features of the pet relation is that things move from being universal exemplars of their species/class to becoming unique individuals. My examination considers petness not as an expression of speciesism, but a challenge to it. To be sure, Peter Singer (1975) dared his readers to consider all animals in the same way as they do pets. ${ }^{7}$

I may be construed as speciesist because I have neglected to talk about humans as potential pets or as nonhuman animals as potential pettakers. I have no doubt that either can be the case. Copeland points out that the term has its origins in human-human relations; that it was applied to women, children, servants, and slaves before nonhumans (2003:112). Undoubtedly, the power-domination and practice of infantilization that characterizes human-pet animal relationships is also common between humans. The task, which is simply beyond the scope of this paper, is to

7. It's worth pointing out that Singer mentions the pet relationship in order to challenge supposed animal lovers to think about the way they treat animals other than pets. In a sense, he suggests that our love and care could/should be extended. However, he dismisses emotionality as the basis for understanding animals' rights and instead endorses a rational approach to consideration. 
examine and clarify how pet emotions differ from similar ones of more egalitarian sentiment and affection. Certainly in the case of humans, one complicated issue concerns the depth of specifically human free will and agency. While there may be a long history of humans using and treating other humans like pets (see Tuan 1984:115-161), such paternalistic views may be vanishing.

At the same time, I recognize that there have been documented cases of animals taking other animals as companions or pets, although Serpell (1989:124-5) claims that this is most likely under conditions of captivity or domestication. Patterson (1987) described one case in her account of the Gorilla, Koko, and her pet cat, All Ball. Patterson characterizes this as a pet relationship because Koko seemingly cared for the kitten as if it were a baby gorilla, by feeding it, playing with it, grooming it, and even nurturing it. Further, Koko purportedly exhibited signs of distress and sadness upon All Ball's death and has since taken other cats as companions. To me, this suggests petness between nonhuman animals is possible. But again, this is a matter for empirical research and beyond the scope of my expertise insofar as it implicates zoological debates concerning the nature of animals' emotions, cognitive capabilities, and so forth.

Whether I diminish or mock the profundity of animal-human affection is somewhat trickier to address beyond the applicable comments above. To a certain degree, my focus falls in line with many of the more radical perspectives which recognize that the pet relation or even the expression itself brings with it domination and mastery (Tuan 1984). In response, some advocate shifting toward metaphors of companionship to highlight the "degree of caring, kindness, consideration and empathy we exchange with the nonhumans who share our lives" (Copeland 2003:112; Smith 2003). But this is an easy way out. Petness is not fundamentally different from "companion animalness" and I could have talked about the latter here since even companion animals are the highly dependent and subordinate "property" of their human friends (Irvine 2004a:5; Grier 2006:7). ${ }^{8}$ Ultimately, this objection stems from a refusal to accept parallels between the way humans experience living creatures and inorganic things. It is a dispute over whether relations between humans and inorganic entities are truly social. This criticism is problematic because it maintains that pet or companion animals are somehow special because they are animate. Again, such a position should be rejected on the grounds that it is essentialist. We cannot pretend animals are related to in a truly distinct manner when some people's experiences and some

8. I do not want to diminish the important (and necessary) gains fostered by the linguistic shift from "pet" to "companion animal." For more on the implications of this move, see Irvine (2004b) or Grier (2006). 
research projects suggest otherwise. The fact that inanimate pets' behaviour is governed by algorithms whereas animate pets' behaviour originates from something different seems to have no bearing on the investment of emotion into, or attribution of human qualities onto, objects.

This is not to say that dogs, cats, hamsters, tamagotchis, furbies, and so on, are not materially different, but materiality does not correlate directly with constitution. Many animate companions likely impose upon our lives in more frequent and profound ways. It is the depth of care and attachment, but not the nature of it, that may differentiate pet object-animals and pet objects. For one thing, pet animals cannot be shut off. They also require long-term emotional and financial commitment. Yet some commonly accepted pets lack such qualities. Humans may live closely with dogs, but fish exist in entirely separate worlds. Other small mammals such as guinea pigs also may be less sensitive to humans than cats, and also arguably so are some robotic pets. Surely this does not mean that these "lower" animals are not truly pets for millions of people. Just as we cannot place the boundary between pets and nonpets at responsive affect emanating from a self, we cannot place it at sentience. Entities are pets if they are experienced as pets. Accordingly, artificial pets cannot be excluded from the pet community. For many virtual pet owners, these beings have intrinsic value. To ridicule this belief would declare that humans' relationships with animals are somehow natural and inherently superior to those with machines. But as Serpell (1986) reminds us, this same attitude has been used to describe people's relationships with pets as inferior to those with humans. Whether such feelings are logically justifiable given that virtual pets are mechanical devices is a topic for another paper.

\section{Conclusion}

This article has illustrated several ways in which sociologists could think more comprehensively about the assumptions that underlie research on pets. The concept of petness has been offered as one possibility for looking at this phenomenon more relationally, and I have tried to make this case by comparing pet animals with artificial pets. I have also attempted to situate petness within larger sociological perspectives concerning relationships in contemporary society. However, this paper has not endeavoured to develop a new theorization of petness. I am proposing we should shift our focus from things, with their own ontological status, to qualities that are (re)constructed and (re)established through interaction. In making this argument, I am proposing that it is the relational quality 
that is an important object of study and my intention is not to diminish the value of the existing work in the field, only to suggest this view provides a starting point for generating new questions. For instance, how can we talk about petness without reifying the pet and giving it a coherent ontological status? Can or should we develop a theory of petness? How can we know, understand and make sense of the idea of the pet? These are difficult subjects, but ones I believe can help provide a better understanding of a critical phenomenon that seems to be multiplying in modern life. This is an imperative undertaking for the sociological discipline in general, and particularly for those working toward a more open field that pays attention to an array of both living as well as nonliving creatures.

\section{REFERENCES}

Archer, John. 1997. Why do people love their pets? Evolution and Human Behavior 18(4):237-259.

Arluke, Arnold and Clinton Sanders. 1996. Regarding Animals. Philadelphia: Temple University Press.

Bauman, Zygmunt. 2003. Liquid Love: On the Frailty of Human Bonds. Cambridge: Polity Press.

Belk, Russell. 1996. Metaphoric relationship with pets. Society and Animals 4(2):121-146.

Bickmore, Timothy. 1998. Friendship and Intimacy in the Digital Age. http:// web.media.mit.edu/ bickmore/Mas714/finalReport.html (09/08/08).

Bingham, Nick. 2006. Bees, butterflies and bacteria: Biotechnology and the politics of nonhuman friendship. Environment and Planning A 38:483-498.

Bloch, Linda-Renée and Dafna Lemish. 1999. Disposable love: The rise and fall of a virtual pet. New Media and Society 1(3):283-303.

Bryant, Clifton. 1979. The zoological connection: Animal related human behavior. Social Forces 58:399-421.

Caporael, L.R. 1986. Anthropomorphism and mechanomorphism: Two faces of the human machine. Computers in Human Behavior 2:215-234.

Copeland, Marion. 2003. The defining difference: Response to "What is a pet?" Anthrozoös 16(2):111-113.

Dautenhahn, Kerstin. n.d. Socially situated life-like agents: If it makes you happy then it can't be that bad. http://www.cyber.rdg.ac.uk/people//people/kd/ www/vwsim.ps $(09 / 13 / 08)$.

Eddy, Timothy. 2003a. What is a pet? Anthrozoös 16(2):98-105. 
2003b. The challenge: Reflections on responses to "What is a Pet?" Anthrozoös 16(2):127-134.

Emirbayer, Mustafa. 1997. Manifesto for a relational sociology. American Journal of Sociology 103(2):281-317.

Flynn, Clifton. 2001. Acknowledging the 'zoological connection': A sociological analysis of animal cruelty. Society and Animals 9(1):71-87.

Friedmann, E., A. Katcher, J. Lnch, and S. Thomas. 1980. Animal companions and one-year survival of patient after discharge from a coronary care unit. Public Health Reports 95:307-312.

Giddens, Anthony. 1991. Modernity and Self-Identity: Self and Society in the Late Modern Age. Cambridge: Polity Press.

Grier, Katherine. 2006. Pets in America: A History. Chapel Hill: North Carolina Press.

Hacking, Ian. 1999. Social Construction of What? Cambridge, MA: Harvard University Press.

Hart, Lynette. 2003. Animals along a continuum: Response to "What is a Pet?" Anthrozoös 16(2):118-122.

Herzog, Werner. 2005. Grizzly Man. Lions Gate Films.

Hochschild, Arlie. 1983. The Managed Heart: Commercialization of Human Feeling. Berkeley: University of California Press.

Huws, Ursula. 2000. Nature, technology and art: The emergence of a new relationship? Leonardo 33(1):33-40.

Irvine, Leslie. 2004a. Pampered or enslaved? The moral dilemmas of pets. International Journal of Sociology and Social Policy 24(9):5-17. 2004b. If You Tame Me: Understanding our Connections with Animals. Philadelphia: Temple University Press.

2007. The question of animal selves: Implications for sociological knowledge and practice. Qualitative Sociology Review 3(1):5-22.

Kahn, Peter, Batya Friedman, Deanne Perez-Gradados and Nathan Freier. 2006. Robotic Pets in the Lives of Preschool Children. Interaction Studies 7(3): 405-436.

Katcher, A., H. Segal, and A. Beck. 1983. Contemplation of an aquarium for the reduction of anxiety. Pp. 171-178 in R.K. Anderson, B. Hart, and L. Hart, eds., The Pet Connection. Minneapolis: University of Minnesota Press.

Kiesler, Tina and Sara Kiesler. 2005. My pet rock and me: An experimental exploration of the self extension concept. Advances in Consumer Research 32:365-370.

Knorr-Cetina, Karin. 1997. Sociality with Objects: Social Relations in Postsocial Knowledge Societies. Theory, Culture and Society 14(4): 1-30. 
Kogan, Lori, Sherry McConnell, Regina Schoenfeld-Tacher, and Pia JansenLock. 2004. Crossroads: A unique foster program to provide safety for pets of women in safehouses. Violence Against Women 10(4):418-434.

Kritt, David. 2000. Loving a virtual pet: Steps toward the technological erosion of emotion. Journal of American and Comparative Cultures 23(4):81-87.

Kruuk, Hans. 2002. Hunter and Hunted: Relationships between Carnivores and People. Cambridge: Cambridge University Press.

Latour, Bruno. 1988a. Mixing humans and nonhumans together: The sociology of a door-closer. Social Problems 35(3):298-310. 1988b. The Pasteurization of France. Cambridge, MA: Cambridge University Press.

Lawrence, Elizabeth. 2003. Some observations on "What is a Pet." Anthrozoös 16(2):123-126.

Marti, P., A. Pollini, A. Rullo, and T. Shibata. 2005. Engaging with artificial pets. Proceedings of the ACM Annual Conference on European Association of Cognitive Ergonomics. Chiana, Greece.

Marx, Karl. 1977. The Economic and Philosophic Manuscripts of 1844. Moscow: Progress.

McCallum, Kathy. n.d. Tamagotchi: An Exploration in Culture. http://www.kerenmerimah.com/projects/thesis/Tamagochi.pdf (08/09/08).

McNicholas, June, Andrew Gilbey, Ann Rennie, Sam Ahmedzai, Jo-Ann Dono, and Elizabeth Ormerod. 2005. Pet ownership and human health: A brief review of evidence and issues. British Medical Journal 331:1252-1254.

Mival, Oli, Steward Cringean and David Benyon. 2004. Personification technologies: Developing artificial companions for older people. Unpublished paper presentation at CHI Fringe: Conference on Human Factors in Computing Systems. Vienna, Austria.

Nancy, J-L. 2000. Being Singular Plural. Stanford: Stanford University Press.

Nast, Heidi. 2006. Critical pet studies? Antipode 38(5):894-906.

Noske, Barbara. 1997a. Beyond Boundaries: Humans and Animals. Montreal: Black Rose Books.

1997b. Speciesism, anthropocentrism, and non-Western cultures. Anthrozoös 10(4):183-190.

Patterson, Francine. 1987. Koko's Kitten. New York: Scholastic Inc.

Pelletier, Caroline. 2005. Reconfiguring interactivity, agency and pleasure in the education and computer games debate - Using Žižek's concept of interpassivity to analyse educational play. E-learning 2(4):317-326.

Plous, Scott. 1993. The role of animals in human society. Journal of Social Issues 49(1):1-9.

Rollin, Bernard and Linda Rollin. 2003. Response to 'What is a Pet?" Anthrozoös 16(2):106-110. 
Sanders, Clinton. 2003. Whose pet? Comment on Timothy Eddy, "What is a Pet?" Anthrozoös 16(2):114-117.

Sanders, Clinton and Arnold Arluke. 1993. If lions could speak: Investigating the animal-human relationship and the perspectives of nonhuman others. The Sociological Quarterly 34(3):377-390.

Serpell, James. 1986. In the Company of Animals: A Study of Human-Animal Relationships. New York: Blackwell. 1989. Humans, animals and the limits of friendship. Pp. 111-129 in Roy Porter and Sylvana Tomaselli, eds., The Dialectics of Friendship. London and New York: Routledge.

Shell, Marc. 1986. The family pet. Representations 15:121-153.

Siegal, Judith. 1993. Companion animals: In sickness and in health. Journal of Social Issues 49(1):157-167.

Singer, Peter. 1975. Animal Liberation. New York: Avon Books.

Smith, Julie Ann. 2003. Beyond dominance and affection: Living with rabbits in post-humanist households. Society and Animals 11(2):181-197.

Tuan, Yi-Fu. 1984. Dominance and Affection: The Making of Pets. New Haven and London: Yale University Press.

Wilson, Edward. 1984. Biophilia. Cambridge, MA: Harvard University Press.

Wright, D. Wynne. 2004. The irrationality of rational hogs. Great Plains Sociologist 16(1).

Wu, Peggy and Christopher Miller. 2005. Results from a field study: The need for an emotional relationship between the elderly and their assistive technologies. http://www.sift.info/English/publications/PDF/Wu-AugCog2005.pdf $(09 / 12 / 08)$

Zizek, Slavoj. 1998. Risk society and its discontents. Historical Materialism 2(1):143-164.

2002. Class struggle or postmodernism: Yes please! Pp. 90-135 in Judith Butler, Ernesto Leclau and Slavoj Zizek, eds., Contingency, Hegemony, Universality: Contemporary Dialogues on the Left. London: Verso.

Jen Wrye is a PhD Candidate and Contract Instructor in the Department of Sociology and Anthropology at Carleton University in Ottawa, Canada. Her research interests include animal-human relations, the sociology of food and eating, and feminist theory.

jenwrye@hotmail.com 
